\section{Influence of Photoinitiator System on Physical-Chemical Properties of Experimental Self-Adhesive Composites}

Marcus Vinicius Loureiro Bertolo ${ }^{1}$, Rita de Cássia Martins Moraes², Carmem Pfeifer $^{3}$, Vinícius Esteves Salgado ${ }^{4,5}$, Ana Rosa Costa Correr ${ }^{1}$, Luis Felipe J. Schneider ${ }^{2,6}$

\author{
'Department of Restorative \\ Dentistry, Dental Materials Area, \\ Piracicaba Dental School, UNICAMP \\ - Universidade Estadual de \\ Campinas, Piracicaba, SP, Brazil \\ ${ }^{2}$ Dental School, UFF - Universidade \\ Federal Fluminense, Niterói, RJ, Brazil \\ ${ }^{3}$ Department of Biomechanics and \\ Biomaterials, Oregon Health \& Science \\ University, Portland, OR, USA \\ ${ }^{4}$ Graduate Program in Dentistry \\ , UFPel - Universidade Federal \\ de Pelotas, Pelotas, RS, Brazil \\ ${ }^{5}$ Dental School, UNIVERSO \\ - Universidade Salgado de \\ Oliveira, Niterói, RJ, Brazil \\ ${ }^{6}$ Nucleus for Dental Biomaterials \\ Research, UVA - Universidade Veiga \\ de Almeida, Rio de Janeiro, RJ, Brazil \\ Correspondence: Marcus Vinícius \\ Loureiro Bertolo, Avenida Limeira, \\ 901, 13414-903 Piracicaba, SP, Brasil. \\ Tel: +55-21-99856-9898. e-mail:
} marcusbertolo@hotmail.com

Key Words: adhesion, resin composite, photoinitiator system, dental materials.

\section{Introduction}

Low-viscosity resin composites were introduced in Dentistry in 1996 (1). Mainly used as liner or as repair material, they could also be applied as filling material in conservative preparations (2). The current novelty in adhesive dentistry is the development of self-adhesive flowable composites (SAFCs) to reduce the clinical time and to decrease the technique sensitivity (3). The SAFCs formulation is based on both conventional methacrylate system and acidic monomers bonding technology derived from self-etching adhesive systems (2). The acidic functional monomers are predominantly methacrylate acid-derivatives, such as 4-methacryloxyethyl anhydride trimellitate acid (4-META), or phosphonate monomers derivatives, such as 2-methacryloxyethyl phenyl phosphate (phenyl-P), methacryloyloxydecyl dihydrogen phosphate (10-MDP), and bis[2-(methacryloyloxy) ethyl] phosphate (2MP) (4). The acidic monomers are capable of chemically interacting with calcium from the tooth substrate, leading to ionic bond (5). However, their low pH may neutralize the tertiary amine by an acid-base reaction, decreasing the composites' polymerization (6). Furthermore, the acidic monomers are more hydrophilic and possibly influenced the increase of water absorption by the polymer.
The traditional photoinitiator system, which includes camphorquinone and a tertiary amine (CO/amine) presents some disadvantages. The $\mathrm{CO}$ absorbs light with a wavelength between 400 and $500 \mathrm{~nm}$, with visible range maximum absorption peak at $468 \mathrm{~nm}$ (7). It presents an intense yellow coloration and requires a co-initiator molecule to optimize the polymerization reaction, which unfortunately may suffer oxidation with time, leading to higher intrinsic discoloration. Furthermore, in acidic media, CO shows limited regeneration (6).

To overcome the $\mathrm{CQ} / \mathrm{amine}$ limitations, alternative photoinitiator systems which do not require a coinitiator, such as the phosphine oxide derivatives diphenyl(2,4,6-trimethylbenzoyl)phosphine oxide (TPO) and phenylbis(2,4,6-trimethylbenzoyl)phosphine oxide (BAPO) could be a viable solution. These molecules are sensitive to wavelengths shorter than $420 \mathrm{~nm}$. This could restrict the use of first and second generations of light-emitting diode (LED) sources, which produce only in the 450-470 $\mathrm{nm}$ wavelength range. Initially proposed to improve the esthetic of conventional resin composite restorations, these systems require large spectrum light sources, like quartz-tungsten halogen lamps or third generation LED 
(8). A previous study has demonstrated the potential use of alternative photoinitiators systems applied to monomeric blends employed in self-etch adhesive systems (9). Assuming that the same could be applied to self-adhesive composite, the purpose of this study was to determine the influence of different photoinitiator systems on the physicalchemical properties of two flowable resin composites types, conventional or self-adhesive, evaluated by the degree of $\mathrm{C}=\mathrm{C}$ conversion, maximum polymerization rate, yellowing effect and water sorption.

The following research hypotheses were tested:

1) self-adhesive resin composites would promote more efficient polymerization and less yellowing degree than conventional composites, when alternative photoinitiator systems were used;

2) self-adhesive resin composites would promote higher water sorption than conventional composites, independent of the photoinitiator system.

\section{Materials and Methods}

\section{Study Design}

This in vitro study involved a $5 \times 2$ factorial study designed to evaluate the performance of model flowable resin composites. The factors were 'photoinitiator system' (5 levels: $C Q+E D M A B, T P O, B A P O, C Q+E D M A B+T P O$ or $\mathrm{CQ}+\mathrm{EDMAB}+\mathrm{BAPO}$ ) and 'flowable resin composite' (2 levels: conventional or self-adhesive). The response variables were degree of $\mathrm{C}=\mathrm{C}$ conversion $(\mathrm{n}=3)$, maximum polymerization rate $(n=3)$, yellowing degree $(n=5)$ and water sorption $(n=5)$.

\section{Formulation of the Model Composites}

The monomers bisphenol-glycidyl dimethacrylate (BisGMA; Esstech Inc., Essington, PA, USA), triethyleneglycol dimethacrylate (TEGDMA, Esstech Inc.) and bis[2(methacryloyloxy) ethyl] phosphate(2MP; Sigma Aldrich, St Louis, MO, USA) were used to prepare two different comonomer formulations: conventional (BisGMA/TEGDMA, 50/50 wt\%) or self-adhesive (BisGMA/TEGDMA/2MP, 30/30/40 wt $\%$ ). Three photosensitizer molecules were used to promote the polymerization reaction: camphorquinone (CO, Sigma Aldrich), diphenyl(2,4,6trimethylbenzoyl)phosphine oxide (TPO, Sigma Aldrich), and phenylbis (2,4,6-trimethylbenzoyl)phosphine oxide (BAPO, Sigma Aldrich). The tertiary amine ethyl-4dimethylaminobenzoate (EDMAB, Sigma Aldrich) was used as a co-initiator for $\mathrm{CQ}$-based materials. Five photoinitiator systems were then created by using different combinations of such molecules: CQ+EDMAB (0.5/1.0 mol\%), TPO (0.5 mol\%), BAPO (0.5 mol\%), CQ+EDMAB+TPO (0.25/0.5/0.25 mol\%) and CO+EDMAB+BAPO (0.25/0.5/0.25 mol\%). After co-monomer and photoinitiator system mixtures, silanized inorganic fillers were added at $45 \mathrm{wt} \%$ for all groups.
This inorganic content was composed of $35 \mathrm{wt} \%$ of $2 \mu \mathrm{m}$ average size barium-aluminum-silicate fillers (Esstech Inc), $35 \mathrm{wt} \%$ of $0.7 \mu \mathrm{m}$ average size barium-aluminum-silicate fillers (Esstech Inc) and $30 \mathrm{wt} \%$ of $50 \mathrm{~nm}$ silicon dioxide fillers (Esstech Inc). All components were measured with $0.0001 \mathrm{~g}$ accuracy in an analytical scale (AX 200; Shimadzu Corporation, Tokyo, Japan) and were mechanically mixed (DAC 150 Speed Mixer; Flacktek, Landrum, SC, USA) for 1 min to produce a homogeneous paste.

\section{Degree of $C=C$ Conversion and Maximum Polymerization Rate}

The degree of conversion was obtained by using nearinfrared (NIR) spectroscopy in $10 \mathrm{~mm}$ diameter and 0.8 $\mathrm{mm}$ thick laminated specimens between two glass slides. The methacrylate $=\mathrm{CH}_{2}$ absorption at $6165 \mathrm{~cm}^{-1}$ (10) was recorded before and after a $40 \mathrm{~s}$ irradiation at $1200 \mathrm{~mW} /$ $\mathrm{cm}^{2}$ (Bluephase G2, Ivoclar Vivadent, Liechtenstein) with the light source in direct contact with the glass slide mold. Real-time monitoring of the polymerization kinetics was carried out in specimens of the same size at 2 scans per spectrum with $4 \mathrm{~cm}^{-1}$ resolution, which provides a greater than $2 \mathrm{~Hz}$ data acquisition rate. Kinetic data were collected continuously for $5 \mathrm{~min}$. Samples ( $n=3)$ were irradiated for $40 \mathrm{~s}$ with a LED curing unit (Bluephase G2).

\section{Yellowing Degree}

A spectrophotometer (Easyshade Compact, Vita Zahnfabrik, Germany) was used to evaluate the yellowing degree by the CIELAB color space. The CIEb* represents the yellow-blue chromaticity coordinate and quantify the yellow (positive values) and blue (negative values). Five specimens were made using a cylindrical metal mold, $8 \mathrm{~mm}$ inner diameter and $2 \mathrm{~mm}$ thick, inserting the materials between Mylar strips (Mylar strips; Preven, PR, Brazil) and photoactivated for $40 \mathrm{~s}$ at $1200 \mathrm{~mW} / \mathrm{cm}^{2}$ (Bluephase G2, Ivoclar Vivadent). The color measurement was conducted with the specimens placed over a white background immediately after photoactivation. For each specimen, three measurements were made and the average was considered the color value.

\section{Water Sorption}

Disc specimens were prepared in a cylindrical metal mold with an $8 \mathrm{~mm}$ inner diameter and $2 \mathrm{~mm}$ thick sandwiched between Mylar strips $(n=5)$. The specific specimen's diameter in this study was obtained in order to promote a homogeneous polymerization, covering all specimen surfaces with the active tip diameter of the light source. The specimens were photoactivated for $20 \mathrm{~s}$ at each side with the light tip in direct contact with the strip. Immediately after curing, the specimens were transferred 
into a desiccator, maintained at $37 \pm 1{ }^{\circ} \mathrm{C}$. After $22 \mathrm{~h}$, the specimens were removed and stored in a second desiccator maintained at $25 \pm 1{ }^{\circ} \mathrm{C}$ for $2 \mathrm{~h}$. Then they were weighed with a $0.0001 \mathrm{~g}$ accuracy analytical scale (AX 200; Shimadzu Corporation). This procedure was repeated until a constant mass was obtained ( $\mathrm{m} 1$ ). Subsequently, the specimens were individually immersed in $10 \mathrm{~mL}$ of distilled water at $37 \pm 1$ ${ }^{\circ} \mathrm{C}$. After 30 days of water storage, replaced every week, the specimens were washed in distilled water, dried with paper towels and reweighed $(\mathrm{m} 2)$. The percentage of water sorption ( $W_{s p}$ ) was calculated by the following equation (9):

$$
W_{s p}=100 \times\left(\left(m_{2}-m_{1}\right) / m_{1}\right)
$$

\section{Statistical Analysis}

Statistical analyses were conducted using SigmaPlot ${ }^{\circledR}$ 13.0 software (Systat Software, San Jose, CA, USA). Data for DC, RPmax, CIE $b^{*}$ and Wsp were analyzed by two-way analysis of variance, considering 'photoinitiator system' and 'flowable resin composite' as factors. The normal distribution of errors was previously checked using ShapiroWilk's test. The heteroscedastic data were transformed to ranks before subjected to statistical analysis. All pairwise

Table 1 . Mean \pm standard deviation values for the degree of $\mathrm{C}=\mathrm{C}$ conversion (\% DC) and maximum rate of polymerization (\% RPmax) for the different photoinitiator systems and flowable resin composite types.

\begin{tabular}{lcccc}
\hline \multirow{2}{*}{ Photoinitiator } & \multicolumn{2}{c}{$\% \mathrm{DC}$} & \multicolumn{2}{c}{$\%$ RPmax } \\
\cline { 2 - 5 } & Conventional & Self-adhesive & Conventional & Self-adhesive \\
\hline CQ+EDMAB & $56.6 \pm 0.5 \mathrm{Ad}$ & $47.6 \pm 0.5 \mathrm{Bd}$ & $8.3 \pm 0.5 \mathrm{Ad}$ & $4.3 \pm 0.5 \mathrm{Bd}$ \\
TPO & $63.0 \pm 1.0 \mathrm{Bb}$ & $69.0 \pm 1.0 \mathrm{Ab}$ & $29.3 \pm 0.5 \mathrm{Aa}$ & $29.3 \pm 1.5 \mathrm{Ab}$ \\
BAPO & $65.3 \pm 0.5 \mathrm{Ba}$ & $70.6 \pm 0.5 \mathrm{Aa}$ & $31.0 \pm 1.0 \mathrm{Ba}$ & $42.6 \pm 3.7 \mathrm{Aa}$ \\
CQ+EDMAB+TP0 & $59.6 \pm 0.5 \mathrm{Bc}$ & $65.3 \pm 0.5 \mathrm{Ac}$ & $18.6 \pm 2.0 \mathrm{Ac}$ & $16.6 \pm 0.5 \mathrm{Ac}$ \\
CQ+EDMAB+BAPO & $61.3 \pm 0.5 \mathrm{Bb}$ & $67.6 \pm 0.5 \mathrm{Ab}$ & $26.3 \pm 0.5 \mathrm{Bb}$ & $31.3 \pm 0.5 \mathrm{Ab}$ \\
\hline
\end{tabular}

Uppercase letters indicate significant differences between flowable resin composite types; lowercase letters indicate significant differences between the photoinitiator systems $(p<0.05)$.

Table 2. Mean \pm standard deviation values for the yellowing degree (CIE $b^{*}$ ) immediately after curing $(n=5)$ and for water sorption (Wsp) after 30 days of water storage $(n=5)$.

\begin{tabular}{lcccc}
\hline \multirow{2}{*}{ Photoinitiator } & \multicolumn{2}{c}{$\mathrm{CIE} \mathrm{b}^{*}$} & \multicolumn{2}{c}{ Wsp } \\
\cline { 2 - 5 } & Conventional & Self-adhesive & Conventional & Self-adhesive \\
\hline CQ+EDMAB & $1.1 \pm 0.1 \mathrm{Bc}$ & $3.7 \pm 0.1 \mathrm{Ac}$ & $1.1 \pm 0.2 \mathrm{Ba}$ & $2.8 \pm 0.6 \mathrm{Ac}$ \\
TP0 & $3.5 \pm 0.2 \mathrm{Bb}$ & $4.3 \pm 0.1 \mathrm{Ac}$ & $1.0 \pm 0.5 \mathrm{Ba}$ & $5.3 \pm 0.2 \mathrm{Aa}$ \\
BAP0 & $11.5 \pm 0.7 \mathrm{Aa}$ & $8.2 \pm 0.2 \mathrm{Ba}$ & $0.7 \pm 0.1 \mathrm{Ba}$ & $5.3 \pm 0.2 \mathrm{Aa}$ \\
CQ+EDMAB+TPO & $1.2 \pm 0.2 \mathrm{Bc}$ & $4.0 \pm 0.1 \mathrm{Ac}$ & $1.0 \pm 0.5 \mathrm{Ba}$ & $3.4 \pm 0.1 \mathrm{Ab}$ \\
CQ+EDMAB+BAPO & $3.8 \pm 0.0 \mathrm{Bb}$ & $6.0 \pm 0.1 \mathrm{Ab}$ & $0.9 \pm 0.1 \mathrm{Ba}$ & $3.5 \pm 0.1 \mathrm{Ab}$ \\
\hline
\end{tabular}

Uppercase letters indicate significant differences between flowable resin composite type; lowercase letters indicate significant differences between the photoinitiator systems $(p<0.05)$. multiple comparison procedures were performed using the Tukey's test $\alpha=0.05)$.

\section{Results} composites, BAPO presented the highest values, followed by TPO and then by $C Q+E D M A B$, which presented the ones. $\mathrm{CQ}+\mathrm{EDMAB}+\mathrm{TPO}$ and $\mathrm{CQ}+\mathrm{EDMAB}+\mathrm{BAPO}$ presented higher $D C$ for self-adhesive materials. Regarding the RPmax, BAPO and TPO presented the highest values for conventional, while BAPO presented hest values for self-adhesive materials. Regardless CQ+EDMAB showed higher RPmax for conventional, while BAPO and $\mathrm{CQ}+\mathrm{EDMAB}$ presented higher RPmax for self-adhesive materials. There was no significant difference between the conventional and self-adhesive resin composites for the TPO and $\mathrm{CO}+\mathrm{EDMAB}+\mathrm{TPO}$ groups.

The yellowing degree (CIE $\left.b^{*}\right)$ and the water sorption (Wsp) results are shown in Table 2. Regarding the CIE $b^{*}$, $\mathrm{BAPO}$, followed by $\mathrm{CO}+\mathrm{EDMAB}+\mathrm{BAPO}$, presented the highest values for both resin composite types. The lowest $\mathrm{CIE} b^{*}$ was presented by CQ+EDMAB and CQ+EDMAB+TPO, for conventional materials, and for selfadhesive materials by $C Q+E D M A B$, CQ+EDMAB+TPO and TPO. Compared with conventional materials, all photoinitiator systems, except for $\mathrm{BAPO}$, presented higher CIE $b^{*}$ for selfadhesive. The yellowing effect follows a general decreasing order BAPO > TPO > CQ+EDMAB for conventional and self-adhesive resin composites. Regarding the $W_{s p}$ results, there was no significant difference among photoinitiator system for conventional materials. TPO and BAPO presented higher Wsp for conventional flowable and self-adhesive materials, while CQ+EDMAB presented the lowest one. All photoinitiator systems presented higher $W_{\text {sp }}$ in self-adhesive materials.

\section{Discussion}

The self-adhesive restorative 
materials were developed aiming to reduce clinical steps. (11). This present study was conducted in order to evaluate the physical-chemical properties of model self-adhesive and conventional resin composites with different photoinitiator systems. The wavelength range for camphorquinone light absorption is different from the alternative photoinitiators. For this reason, in this study was used the large spectrum light-emitting diode curing unit for photo-activation. This curing unit has an emission peak around $460 \mathrm{~nm}$ to initiate the CQ/amine system and an additional peak around 400 $\mathrm{nm}$, suitable to excite the phosphine oxide derivatives, TPO and BAPO.

The first research hypothesis was rejected. Although the self-adhesive composites have shown more efficient polymerization with alternative photoinitiators systems, this did not occur for the yellowing degree. The self-adhesive materials exhibited higher DC than the conventional ones and this may be explained by the lower concentration of BisGMA in the self-adhesive materials compared with the CFC series. Due to the high molecular weight and its chemical structure, the BisGMA monomer provides high viscosity (12). The hydroxyl groups present in the aliphatic portion of BisGMA form intermolecular bonds by hydrogen bonds, which increases the interaction between molecule chains and thus decreases their mobility (13). Due to this low mobility during the polymerization reaction, the DC tends to reduce as the BisGMA concentration increases (14).

In this study, the CQ+EDMAB-based SAFCs presented lower $\mathrm{DC}$ and $\mathrm{RP}_{\max }$ values than that in the CFC series. Furthermore, comparing the photoinitiator systems in the SAFC series, CQ+EDMAB+TPO- and CQ+EDMAB+BAPObased materials presented higher $\mathrm{DC}$ and $\mathrm{RP}_{\max }$ than the ones formulated with CO+EDMAB. Those outcomes may be explained by the fact that an acid-base reaction can be formed between the acidic monomers and tertiary amines, transforming the amine into a protonated form, which is unable to act as the polymerization co-initiator (6). Since TPO and BAPO do not require a co-initiator to optimize the polymerization reaction (15), the materials formulated with them do not have obstacles to polymerize.

BAPO-based materials presented the highest DC and $\mathrm{RP}_{\max }$ results compared with other groups. BAPO has an increased efficiency in free radicals generation, higher than TPO and CO. Following the light energy absorption, this molecule undergoes an $\alpha$-cleavage in the excited triplet state of the C-P bond, which may occur twice, with the ability to generate four free radicals per molecule (16), while TPO can generate two and CO only one (17). Furthermore, BAPO and TPO have higher molar absorption coefficients than $\mathrm{CO}$, which means that those compounds absorb more light than $\mathrm{CO}$ at the corresponding maximum absorption peak (18).
The self-adhesive materials exhibited higher yellowing degree than conventional materials, except for BAPO-based groups. According to the monomers MSDS of the present study, 2MP (19) and BisGMA (20) are slightly yellow, while TEGDMA (21) is colorless. The SAFCs have higher concentrations of slightly yellowish monomers (70\%) than the conventional ones (50\%). Moreover, as a consequence of acid-base reaction between EDMAB and $2 \mathrm{MP}$, lower amount of $\mathrm{CQ}$ is consumed during the polymerization reaction. The non-consumed CQ provides an intense yellow coloration to the material. For these reasons, it may be supposed that the self-adhesive materials may present higher yellowing degree than the conventional ones.

BAPO provides higher yellowing degree to both materials after curing. Before curing, $\mathrm{CQ}$ is more yellow than BAPO and TPO (22). However, the polymerization reaction leads to molecule decomposition, causing a photobleaching effect (decrease in $\mathrm{CIE} b^{*}$ ) by photo-reduction mechanism (23). It was already reported that $\mathrm{CO}$ showed higher photo-bleaching effect than BAPO (22), which in this study could explains the higher CIE $b$ *results of BAPO-based materials after curing. In addition, TPO and BAPO produce rapid polymerization rates. Therefore, the temperature rises, which may cause colored peroxides formation and a significant yellow discoloration (23). TPO has lower yellow degree relatively to BAPO, which is probably due to the higher TPO molar absorption coefficient, which leads to more TPO molecules consumption during the polymerization reaction (17). Furthermore, before curing BAPO provides more yellowing than TPO (22).

The second research hypothesis was accepted. All self-adhesive materials presented higher water sorption than the conventional ones. In a resin composite, the polymer network should ideally be insoluble and possess chemical and thermal stabilities (24). However, the polymer network absorbs water and chemical components from the environment, which may cause deleterious effects on the structure and compromises the polymeric material function, including chemical, physical or volumetric changes (25). The higher water sorption of SAFCs may be explained by the addition of ionic hydrophilic monomers in the polymer network, increasing the material's affinity to water produced by higher formation of hydrogen bonds (24).

Based on the results from this study it may be concluded that the photo initiator system affected differently the physical-chemical properties of the conventional and self-adhesive flowable resin composites. Regardless of photoinitiator system, the self-adhesive materials presented the yellow coloration and water sorption than conventional materials. The $\mathrm{CQ}+\mathrm{EDMAB}+\mathrm{TPO}$ group presented satisfactory results in all physical-chemical analyses. 


\section{Resumo}

0 objetivo do estudo foi determinar a influência do sistema fotoiniciador sobre as propriedades físico-químicas de compósitos fluidos. Os compósitos convencionais foram compostos por bisfenol-glicidil dimetacrilato (BisGMA) + trietilenoglicol dimetacrilato (TEGDMA), e os autoadesivos, apresentavam BisGMA +TEGDMA+Bis[2(metacriloiloxi)etil] fosfato (2 MP). Cinco sistemas fotoiniciadores foram testados: canforquinona + etil-4dimetilamino benzoato (CO+EDMAB), óxido mono-alquil fosfínico (TPO) e óxido bis-alquil fosfínico (BAPO), $C Q+E D M A B+T P O$ e $C O+E D M A B+B A P O$. LED de amplo espectro foi usado; o grau de conversão (GC) e a taxa de polimerização (TP) foram determinados por espectroscopia próximo ao infravermelho; o grau de amarelo foi mensurado por um espectrofotômetro e absorção de água foi obtida após 30 dias de armazenamento em água $(n=5)$. Os dados foram submetidos a análise de variância de dois fatores e teste de Tukey $(\alpha=0,05)$. BAPO apresentou os maiores valores de GC e TP nos compósitos convencionais e autoadesivos. Compósitos autoadesivos apresentaram menor GC e TP quando CQ+EDMAB foi usado. Maior amarelecimento foi observado nos compósitos autoadesivos em relação aos convencionais, exceto para BAPO. Compósitos autoadesivos promoveram maior absorção de água. Não houve influência dos fotoiniciadores nos compósitos convencionais, no entanto TPO e BAPO apresentaram os maiores valores de absorção de água nos compósitos autoadesivos. Os sistemas fotoiniciadores influenciaram de maneira diferente as propriedades físico-quimicas dos compósitos convencionais e autoadesivos.

\section{References}

1. Bayne SC, Thompson JY, Swift EJ, Stamatiades P, Wilkerson M. A characterization of first-generation flowable composites. J Am Dent Assoc 1998;129:567-577.

2. Malavasi CV, Macedo EM, Souza C, Rego GF, Schneider LF, Cavalcante LM. Surface texture and optical properties of self-adhering composite materials after toothbrush abrasion. J Contemp Dent Pract 2015;16:775-782.

3. Bektas 00, Eren D, Akin EG, Akin H. Evaluation of a self-adhering flowable composite in terms of micro-shear bond strength and microleakage. Acta Odontol Scand 2013;71:541-546.

4. Ferracane JL. Resin composite - State of the art. Dent Mater 2011;27:29-38.

5. Van Meerbeek B, Yoshihara K, Yoshida Y, Mine A, De Munck J, Van Landuyt KL. State of the art of self-etch adhesives. Dent Mater 2011;27:17-28.

6. Guo X, Peng Z, Spencer $P$, Wang $Y$. Effect of initiator on photopolymerization of acidic, aqueous dental model adhesives. J Biomed Mater Res A 2009;90:1120-1127.

7. Segreto DR, Naufel FS, Brandt WC, Guiraldo RD, Correr-Sobrinho L, Sinhoreti MA. Influence of photoinitiator and light-curing source on bond strength of experimental resin cements to dentin. Braz Dent J 2016;27:83-89.

8. Price RB, Felix CA. Effect of delivering light in specific narrow bandwidths from 394 to $515 \mathrm{~nm}$ on the micro-hardness of resin composites. Dent Mater 2009;25:899-908.
9. Sodre CS, Albuquerque PPAC, Isolan CP, Moraes RR, Schneider LF. Relative photon absorption determination and the influence of photoinitiator system and water content on $\mathrm{C}=\mathrm{C}$ conversion, water sorption/solubility of experimental self-etch adhesives. Int J Adhes Adhes 2015;63:152-157.

10. Stansbury JW, Dickens SH. Determination of double bond conversion in dental resins by near infrared spectroscopy. Dent Mater2001;17:71-79.

11. Moszner N, Salz U, Zimmermann J. Chemical aspects of selfetching enamel-dentin adhesives: A systematic review. Dent Mater 2005;21:895-910.

12. Moreira FC, Antoniosi FNR, Souza JB, Lopes LG. Sorption, solubility and residual monomers of a dental adhesive cured by different light-curing units. Braz Dent J 2010;21:432-438.

13. Stanbury JW, Dickens SH. Network formation and compositional drift during photo-initiated copolymerization of dimetacrylate monomers. Polymer 2001b;42:6363-6369.

14. Ferracane JL, Greener EH. The effect of resin formulation on the degree of conversion and mechanical properties of dental restorative resins. J Biomed Mater Res 1986;20:121-131.

15. Stanbury JW. Curing dental resins and composites by photopolymerization. J Esthet Dent 2000;12:300-308.

16. Meereis CT, Leal FB, Lima GS, de Carvalho RV, Piva E, Ogliari FA. BAPO as an alternative photoinitiator for the radical polymerization of dental resins. Dent Mater 2014;30:945-953.

17. Neumann MG, Miranda WG Jr, Schmitt CC, Rueggeberg FA, Correa IC. Molar extinction coefficients and the photon absorption efficiency of dental photoinitiators and the light curing units. J Dent 2005;33:525532.

18. De Oliveira DC, Rocha MG, Gatti A, Correr AB, Ferracane JL, Sinhoreti MA. Effect of different photoinitiators and reducing agents on cure efficiency and color stability of resin-based composites using different LED wavelengths. J Dent 2015;43:1565-1572.

19. Bis-2-methacyloyloxy-ethyl phosphate; PRD.1.Z05.10000005421; Sigma-Aldrich; Saint Louis, MO 6313, USA.

20. Bisphenol glycidyl dimethacrylate; PRD.1.Z05.10000007932; SigmaAldrich; Saint Louis, MO 6313, USA.

21. Triethyleneglycol dimethacrylate; PRD.3.Z05.10000009625; SigmaAldrich; Saint Louis, M0 6313, USA.

22. Albuquerque PPAC, Moreira ADL, Moraes RR, Cavalcante LM, Schneider LFJ. Color stability, conversion, water sorption and solubility of dental composites formulated with different photoinitiator systems. J Dent 2012; 67-72.

23. Hadis MA, Shortall AC, Palin WM. Competitive light absorbers in photoactive dental resin-based materials. Dent Mater 2012;28:831841.

24. Malacarne J, Carvalho RM, de Goes MF, Svizero N, Pashley DH, Tay FR, et al.. Water sorption / solubility of dental adhesive resins. Dent Mater 2006;10:973-980.

25. Ferracane JL. Hygroscopic and hydrolytic effects in dental polymer networks. Dent Mater 2006;22:211-222. 